\section{Complete Involution of the Breast as Initial Presentation of Carcinoma}

Received: March 08, 2016; Accepted: March 10, 2016; Published: March 14, 2016

\section{Kadiri S, Berhili S, Kebdani T and Benjaafar $\mathbf{N}$}

\author{
Department of Radiotherapy, National \\ Institute of Oncology, Rabat
}

\section{Corresponding author: \\ Kadiri Selma \\ ” kadiri.selma@gmail.com}

\begin{abstract}
A 54 year-old woman with no previous medical history was admitted with complaint of an almost complete retraction of the left breast with lymphoedema of the ipsilateral arm. The disease was evolving for 10 years. Physical examination revealed a complete involution of the left breast with 3 underskin nodules in its upper external quadrant over hanging a $30 \mathrm{~mm} \times 10 \mathrm{~mm}$ lump (Figures 1 and 2).
\end{abstract}

In addition to that 2 lymphadenopathies were found in the left axillae and confirmed by ultrasonography.

The diagnosis of carcinoma of the breast was confirmed by immunohistochemical studies, after biopsies of the parietal nodules and the axillary lymphadenopathies. Cancer cells were positive for ER (reactivity 90\%) and PR (reactivity 90\%) and negative for herceptest test (HER2).

The workup, including thoracic computed tomography, abdominal ultrasonography and a bone scan, found no evidence of metastatic disease. The patient was staged with a locally advanced breast cancer (T4bN1M0). A board meeting made the decision to do neaodjuvant chemotherapy and consider surgery, adjuvant radiotherapy and endocrine therapy. The patient had 6 cycles of chemotherapy: 3 of doxorubicin and cyclophosphamid (AC60) and 3 of paclitaxel. A complete regression of the lymphoedema was considered as a good clinical response. The patient was referred to the surgery department and is going to have radical surgery with axillary lymph node dissection.

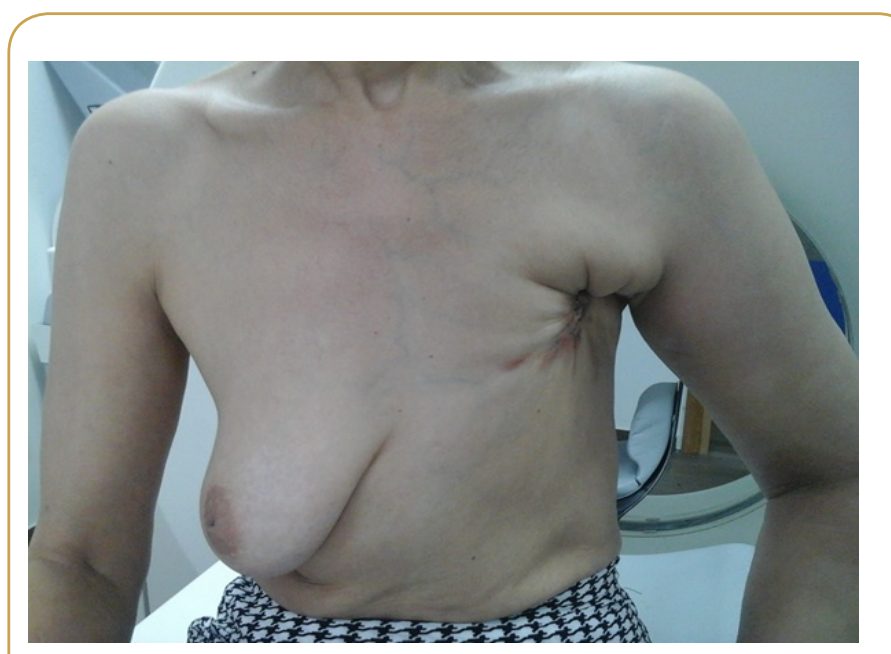

Figure 1 Image showing the complete involution of the left breast.
Resident of Radiation Oncology, Department of Radiotherapy, National Institute of Oncology, Rabat, Morocco.

Tel: +1-2068972800

Citation: Kadiri S, Berhili S, Kebdani T, et al. Complete Involution of the Breast as Initial Presentation of Carcinoma. Arch Cancer Res. 2016, 4:1.

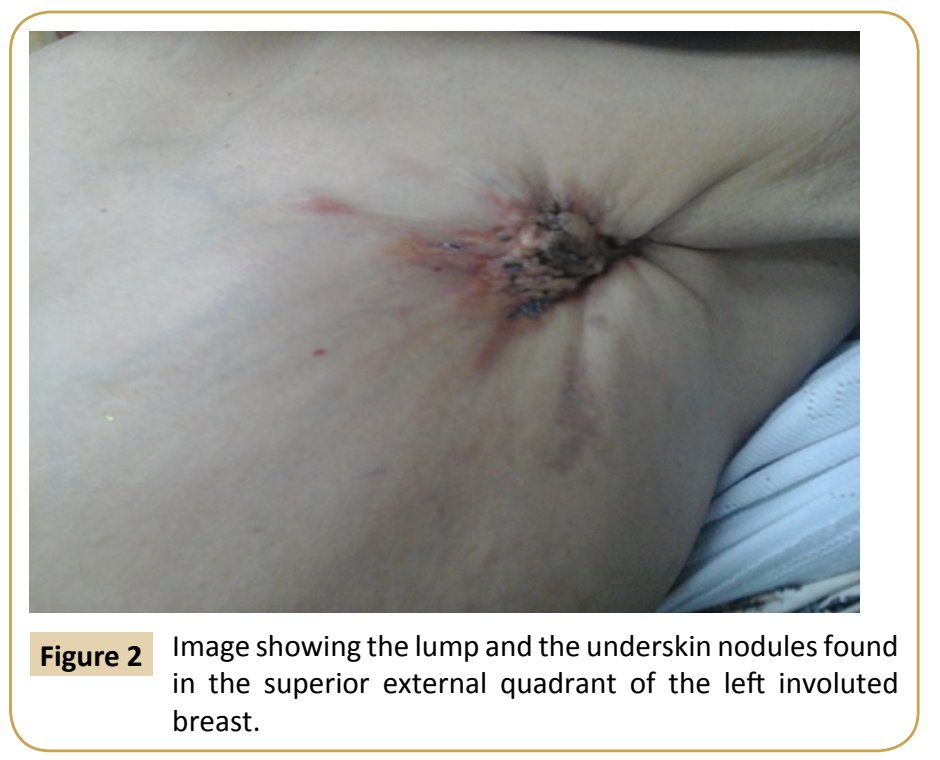

